\title{
Lights, building, action: Impact of default lighting settings on occupant behaviour
}

\begin{abstract}
Occupant behaviour and their interactions with building systems could significantly influence energy consumption in buildings. Studies suggest "default setting" techniques could be used as intervention strategies as people's preferences are dramatically influenced by minor variations in settings. With the goal to reduce lighting-related energy consumption, we study the effects of default lighting settings on occupants' rate of lighting adjustments in a single occupancy office space. Through the use of immersive virtual environments, we analysed 160 participants' data in a virtual office space. Based on the results, people are significantly more likely to keep the lighting settings if the default condition had some or maximum daylighting available. Additionally, the participants reading speed and comprehension were respectively faster and more accurate in conditions where simulated daylight was available. By using default settings, we can influence occupant behaviour towards more energy efficient choices in their daily interactions with building's lighting and shading systems.
\end{abstract}

Keywords: Default Setting; Lighting; Immersive Virtual Environments; Occupant Behaviour; Occupant-Building Interactions

\section{Introduction}

Due to high and increasing share of buildings in energy consumption, we have seen significant improvements during the last decade in building design (e.g., intelligent facades, green roofs, etc.), building technologies (e.g., automated lighting/shading systems, smart grid, etc.) and building operational strategies (e.g., occupancy driven HVAC control, etc.) that have provided various opportunities to reduce energy consumption in buildings. Although these improvements are promising, research suggests in order for such improvements to be fully effective, it is important for architects, engineers, and facility managers to understand the relationships between occupant behaviour and building energy consumption (Carrico \& Riemer, 2011; Li, Hong, \& Yan, 2014; Sieminski, 2013). The way that occupants interact with lighting systems can significantly affect the amount of energy that a building consumes. If we are able to better understand how occupants use and interact with such systems, we can design and operate buildings to be more energy efficient while also increasing occupant satisfaction.

Supporting this notion, prior research has shown that the design and operation of buildings can affect what type of lighting occupants use and how occupants interact with lighting systems (Boyce, et al., 2006; Li, et al., 2014; Moore, Carter, \& Slater, 2003). For example, studies have shown that increasing the available daylighting in an office space can lead occupants to use less electric light, resulting in a lower total energy consumption in buildings (Galasiu \& Veitch, 2006). In addition to reducing energy consumption, studies indicate that increasing natural lighting can also improve occupant's mood (Edwards \& Torcellini, 2002), performance (Heerwagen, 2000), and well-being (Galasiu \& Veitch, 2006). Other studies have also found increase in daylighting in an office environment could result in lower absenteeism and higher financial savings (Edwards \& Torcellini, 2002; Thayer, 1995). Meanwhile, research shows that buildings with poor daylighting (e.g., inadequate natural lighting, glare, overheating, etc.) tend to consume more energy due to higher use of electric lighting and increased interactions with shading and electric lighting systems (Dubois \& Blomsterberg, 2011).

Design and operation of a building not only influence the amount of electric light that occupants use, but also influence the amount of interaction occupants have with lighting systems. For example, lighting research suggests that occupants are less likely to adjust the shades if the available lighting is within their acceptable levels and enough to perform daily activities (Dubois \& Blomsterberg, 2011; O'Brien, Kapsis, 
\& Athienitis, 2013; Van Den Wymelenberg, 2012). In their studies, Reinhart and Voss (2003) and Moore, et al. (2003) conclude that most of the 'switching-on' events take place upon an occupant's arrival, and afterwards the lighting settings stay unadjusted throughout the day. These studies identify two factors that significantly influence the 'switching-on' behaviour: personal factors about the occupants (e.g., personality, mood, etc.) and the available natural lighting outside. Similarly, Sanati and Utzinger (2013) observed that once the interior shadings were lowered, they were left in place for days or weeks without any adjustment. In order to influence occupant's lighting setting choices and their interaction with electric lighting and shading systems, it is essential to influence their behaviour upon their arrival to their office space. Even illuminance preferences of occupants can be influenced by building design. For example, occupants' preferred lighting is significantly influenced by the range of available illuminance, and therefore, different illuminance ranges result in different lighting preferences (Begemann, Van den Beld, \& Tenner, 1997; Moore, et al., 2003; Veitch \& Newsham, 2000; Wei, et al., 2014). Further, supporting this notion, (Fotios \& Cheal, 2010; Logadóttir, Christoffersen, \& Fotios, 2011) suggest that the mean preferred illuminance changes when occupants are given the same tasks but different ranges of available illuminances. In summary, through various interventions occupants lighting perception and preferences could be influenced.

Building off of the prior research, in this paper, we investigated how default lighting settings with simulated daylighting and/or electric lighting could influence participants' lighting choices with the objective of (1) increasing the use of daylighting in office spaces, and (2) decreasing interactions with electric lighting systems. Since occupants have the tendency to adjust the lighting settings upon arrival and their lighting choices are influenced by building design and operations, setting lighting to default conditions could be an effective approach to influence their lighting choices. More specifically, we investigated whether default settings with simulated daylighting have more influence on participants' preferred lighting settings in comparison to default settings with electric lighting; such that participants' final lighting choice would be more energy efficient if daylighting is presented as an initial (default) setting (rather than electric light). As an experimental tool, we used an immersive virtual environment (IVE) to place participants in a virtual office space in order to perform a set of office related activities while having the freedom of keeping or adjusting the default lighting settings. In the next two sections, we provide a brief overview of the literature on default setting's influence on human behaviour and our motivation to use an IVE setting to collect participant's data. We then present our research methodology, data acquisition, experimental procedure, analysis and results of the experiment, and discussion and conclusions of our study.

\section{Default settings and human behaviour}

Z. Brown, Johnstone, Haščič, Vong, and Barascud (2013) identified feedback mechanism, social comparison, commitment devices, and manipulation of default options as the four classes related to behavioural interventions that could influence energy consumption behaviour. Default options are defined as pre-selected settings that a person in charge does not need to make any adjustments or changes to if they so desire. These options are used commonly where there is a desired behaviour as an outcome of people's choices (Davidai, Gilovich, \& Ross, 2012; Gilovich \& Griffin, 2010). For example, one of the most famous studies on default options was performed by Choi, Laibson, Madrian, and Metrick (2002), where they assessed the effects of several different 401(k) plans (e.g., automatic cash distribution, investment options, etc.) on people's saving behaviour. In their study, the authors identified that employees follow the path of "least resistance" and thus are more likely to choose the default option. With this knowledge, administrators can change the default to be the most beneficial plan for the employee. In a more recent study, Choi, Laibson, Madrian, and Metrick (2004) found that automatically enrolling employees in a 401(k) plan dramatically impacts their retirement savings behaviour. Other studies have examined the influence of default settings on organ donor rates in the healthcare system (Davidai, et al., 2012; Johnson \& Goldstein, 2003). For instance Davidai, et al. (2012) found that the rate 
of donors in countries with policies where citizens must indicate their "willingness" to have their organs harvested in an event of an accident reaches approximately $15 \%$ but this rate exceeds $90 \%$ in countries with policies where citizens must indicate their "unwillingness" to have their organs harvested. Other decision-making studies in various domains, such as insurance choices (Johnson, Hershey, Meszaros, \& Kunreuther, 1993), consumer research (C. L. Brown \& Krishna, 2004), and internet privacy (Johnson, Bellman, \& Lohse, 2002), have also identified that people do not switch to another alternative when put in a certain default setting.

Similarly, a number of studies have evaluated the impact of default options on environment-related tasks (Fotios \& Cheal, 2010; Logadóttir, et al., 2011). For instance, in observational and experimental settings, (Pichert \& Katsikopoulos, 2008) discovered that by switching the default selection of the electricity from "grey" source (e.g., coal, where electricity is generated from a harmful source of energy) to a more "green" (less polluting) source, we can significantly increase the adoption rate of green electricity among people. In another study, Z. Brown, et al. (2013) conducted an experiment to test whether thermostat defaults influence people's behaviour. They concluded that providing small changes in the defaults of office thermostats lead to lower temperature settings in the winter heating season, therefore, resulting in lower energy consumption in buildings. Additionally, in a controlled experimental setting, de Korte, et al. (2015) measured the influence of direct and indirect illuminance, as well as pre-set and adjusted lighting settings by the participants. They discovered that higher pre-set values lead to higher adjusted operative temperatures and higher illuminances on a desk. One of the major limitations in some of these studies is that in order to remove confounds and eliminate variations in illuminance levels due to natural lighting, the experimenters block daylighting in their studies and only focus on participants' interactions with the electric lighting systems. However, by increasing daylighting in office buildings, we can significantly reduce the lighting-related energy consumption. In this paper, we investigate how defaults can be used to increase use of simulated daylighting and decrease rate of electric lighting adjustments, resulting in less lighting-related electricity consumption.

\section{Motivation for using immersive virtual environments}

Due to the many factors that can influence human behaviour (e.g., spatial, environmental, societal, personal factors), energy simulations that are used during the design stage do not usually provide realistic representations of occupant behaviour and may result in under or overestimation of energy consumption in buildings (Yu, Fung, Haghighat, Yoshino, \& Morofsky, 2011). Similarly, technological advancements, used during the operation phase of buildings, do not lead into low energy consumption since most of these technologies are operated by occupants, and therefore, influenced by occupants' behaviour (Hong, D'Oca, Turner, \& Taylor-Lange, 2015; Nilsson, Andersson, \& Bergstad, 2015). Observational and experimental studies that examine occupant behaviour in buildings increase the possibility of experimental noise as they often cannot keep the design features (e.g., interior design, surface reflection, etc.) or environmental features (e.g., weather, available daylighting) constant throughout the course of the study. These effects could be easily ignored or not noticed during the experiment and data collection process. For instance, as part of the limitations in their study, (Maniccia, Rutledge, Rea, \& Morrow, 1999) mentions the variations in interior design (e.g., desk location and orientation) could have impacted the shading and dimmer use by occupants. Additionally, these studies are limited in terms of their size and generalizability (e.g., small number of participants, limited number of case studies, etc.). Therefore, in our study, we used Immersive Virtual Environments (IVE), as an approach to (1) investigate human behaviour in an office space and (2) reduce the experimental noise that is not possible to control for in a physical space (i.e., daylighting).

With the current advancements in the fields of augmented and virtual reality, we are now able to create realistic virtual environments where users can be fully immersed and feel similar sense of presence as physical environments (Adi \& Roberts, 2014; Heydarian, Carneiro, et al., 2015). In recent years, many domains (e.g., psychology, medical, education, military, and etc.) have adapted virtual reality tools for 
training purposes, as well as to better understand human behaviour and decision making in various situations and settings (Bosch-Sijtsema \& Haapamäki, 2014; De Lillo \& James, 2012; Duarte, Rebelo, Teles, \& Wogalter, 2014; Larsen, Oestergaard, Ottesen, \& Soerensen, 2012; Parsons, 2014; Pertaub, Slater, \& Barker, 2002; Tanja-Dijkstra, et al., 2014; Waller, Beall, \& Loomis, 2004). Kuliga, Thrash, Dalton, and Hölscher (2015) suggests that these environments provide us with the capability to systematically manipulate different environmental settings, which cannot be easily implemented in realworld environments. These environments allow researchers and practitioners to manipulate their variables of interest (e.g., different default lighting settings) while keeping other features constant (e.g. interior design, sky conditions, view), resulting in more accurate experimental settings and reduced experimental noise compared to the studies conducted in physical environments. For instance, IVEs provide the opportunity to designers to create virtual mock-ups of buildings where the stakeholders and users can be immersed in and interact with a variety of design features in order to evaluate alternatives and provide feedback during the design phase (Majumdar, Fischer, \& Schwegler, 2006; Maldovan, Messner, \& Faddoul, 2006). In another example, during the design phase of a hospital, Dunston, Arns, Mcglothlin, Lasker, and Kushner (2011) used IVEs to get design feedback from end-users (e.g., doctors and nurses) as well as the patients. As part of their findings, the authors concluded that IVEs were highly effective tools to get feedback from the end-users during the design phase. In behavioural research, these environments also provide the researchers with the capability to collect detailed measurements (e.g., participant's navigational decision making, direction and field of view, and preferential information) under controlled settings.

In order to measure the influence of simulated daylight vs. electric lighting default settings on the participants' preferred lighting choices, experimenters must be able to overcome the lack of control on daylighting illuminance variations. To be able to keep the available daylighting constant and identical among participants, if the virtual environments are realistically configured, participants can provide similar responses as they would in physical environments. Therefore, in our study, we utilized IVEs to design a virtual office space with realistic interior designs (e.g., tables, chairs) and lighting features (e.g., daylighting, shades, light switches, realistic luminance and illuminance) that a physical office would have. Additionally, to keep this experiment internally valid, by using IVEs, we were able to eliminate confounds that could have influenced participants final lighting choices such as, outside view, noise, sources of lighting (e.g., computer screens) and etc.

\section{Research methodology}

Our objective in this paper is to evaluate how the concept of "default settings" can be used in commercial buildings in order to reduce the lighting-related electricity waste by increasing the use of daylighting in offices and decreasing electric lighting (consequently reducing electricity consumption), while ensuring the lighting levels are within the occupants' acceptable settings. We have selected five default lighting conditions (Figure 1) that the participants can perform daily office related activities in an IVE. These conditions were (a) a room with all shades open (three shades) and no fluorescent lamps on (maximum simulated daylight only), (b) a room with all shades open and one fluorescent lamp turned on, on each light fixture, (c) a room with all shades closed and two fluorescent lamps on for each light fixture, (d) a room with all shades closed and three fluorescent lamps on (maximum electric light only), and (e) a room with all shades open and three fluorescent lamps on (maximum lighting). Specifically, we explored the participants' propensity to keep or adjust the default lighting settings when simulated daylighting was available vs. when only electric lighting was available in order to better understand the effects of such default settings on participants' behaviour.

We evaluated 160 (74 females and 86 males) participants' interactions with the electric lighting and shading systems when assigned to perform a set of activities in a virtual office space. A power analysis confirmed that the sample size was sufficient to detect significant effects at a power of 0.85 . The participants were students at the University of Southern California (USC) between the ages 18 to 32 
(Mean $=22$, Median $=21, \mathrm{SD}=2.9$ ). Based on the participants' interactions with the virtual space (i.e., keeping or adjusting the default lighting setting) and their responses to a set of questionnaires, we analysed how default lighting settings could influence lighting choices, performance, and whether individual's environmental views and values affect participants' propensity to change the default conditions. Additionally, we asked participants to fill out the Big Five personality test (John \& Srivastava, 1999) in order to examine whether their personality traits had an influence on their propensity to keep or adjust the default settings.

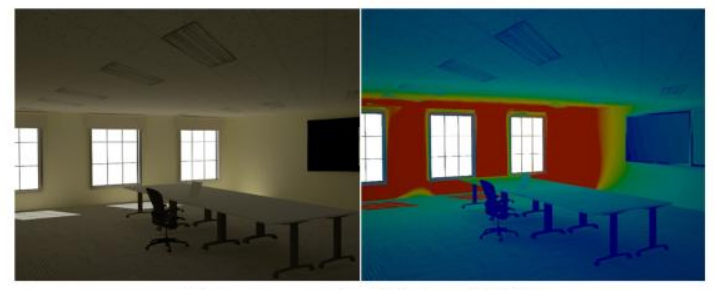

a. All shades open \& all lights off (0111)

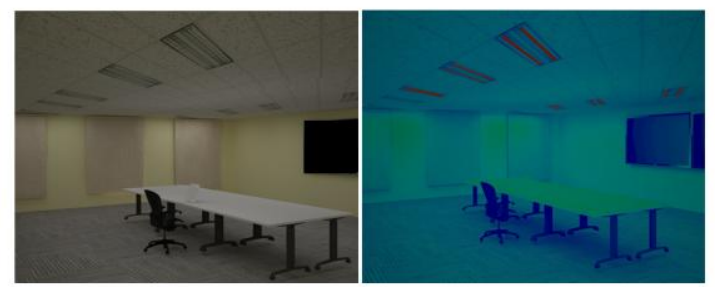

c. All shades closed \& two lights on (2000)

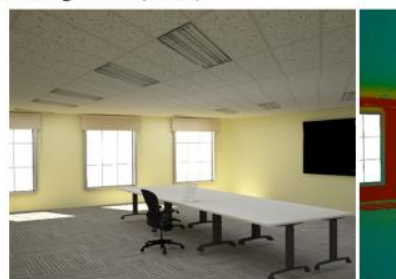

e. All blinds open \& all lights on (3111)

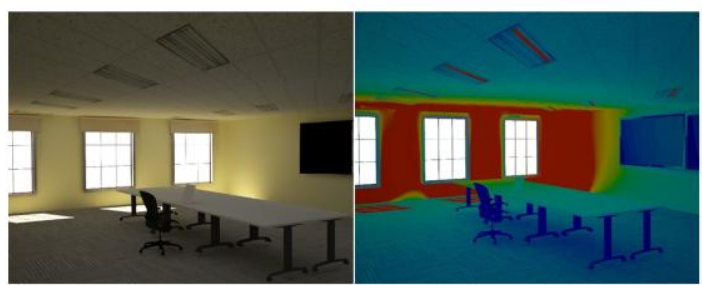

b. All shades open \& one light on (1111)

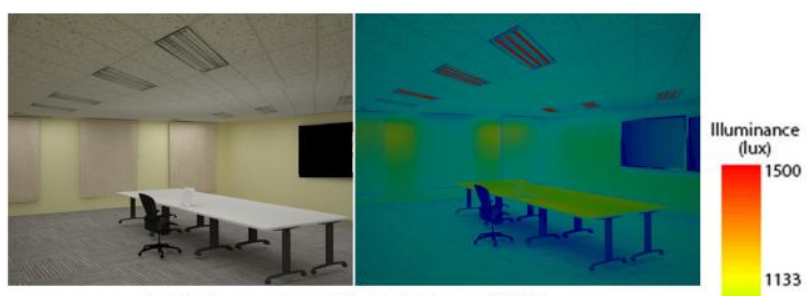

d. All shades closed \& all lights on (3000)
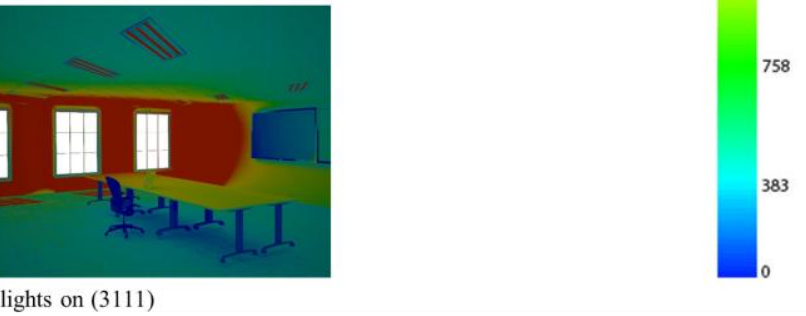

Figure 1 - The five default lighting settings used in this study. Each set of images show the rendered images along with the falsecolor images of the office space.

\subsection{Experiment design and analyses}

In order to evaluate our research objective, a virtual office space was designed similar to an actual existing office space (Figure 1). The designed room was 50 square meters in size, and included three windows facing south (each had a manually controlled shade), as well as 12 light fixtures (three fluorescent lamps on each fixture). Each shade was designed to be only fully open or fully close. The light switches in the room were designed in a way that a participant could adjust the electric lighting to have one, two, or three lamps on for each light fixture. Therefore, 32 different lighting setting combinations (shading systems and electric lighting system) were possible to be selected by participants as their "preferred setting." Throughout this paper, a naming convention is used to clearly identify what lighting setting the participants prefer. This naming convention consists of four numbers, in which the first number indicates how many fluorescent lamps are on, and the next three numbers indicate whether each shade is open or closed ( 0 indicates a specific shade is closed and 1 indicates that the shade is open). For instance, we identify a room which has two fluorescent lamps on as well as the right and middle shades open while the left shade is closed as " 2110 " (Figure 2). 
Figure 2 - Naming convention used in this paper to refer to different lighting settings

The participants were randomly assigned to one of the five default lighting settings:

- Group 1 (0111): all three shades are open while all lamps are turned off.

- Group 2 (1111): all three shades are open while only one of the three lamps is turned on.

- Group 3 (2000): only two lamps are turned on while all the shades are closed.

- Group 4 (3000): all three lamps are turned on while all the shades are closed.

- Group 5 (3111): all three lamps are turned on, while all three shades are open (maximum available lighting).

We carefully designed the experiment to only manipulate our variables of interest (simulated daylighting vs. electrical lighting) and avoid possible confounds. To eliminate any confounds due to the time of day, we conducted the experiments consistently between 11:00 AM to 4:00 PM for a period of three months (March-May 2015), where enough natural light was available outside. The 3D models were also designed to reflect the sun position at 2:00 PM at the same location and time of the year. Similarly, in order to ensure participants' choices are driven by lighting preference rather than a desire to see a view, we eliminated the outside view by replacing the view with a blue sky. Previous research has shown that an outside view has a significant influence on the occupants' interactions with the shading systems (Aries, Veitch, \& Newsham, 2010; Matusiak \& Klöckner, 2016; Tuaycharoen \& Tregenza, 2007). Since we were specifically interested in the influence of simulated daylighting vs. electric lighting on the participants' tendency to keep the default settings, it was important to eliminate view and other possible confounds, only manipulating our variables of interests (available daylight vs. electric lighting). To ensure participants did not assume there was a view, before the experiment took place they were informed that there will be no specific view outside the windows (just the blue sky). To effectively measure the influence of default settings, the following comparisons were performed:

- 2000 and 3000 vs. 0111, 1111, and 3111: to measure the influence of maximum simulate daylighting vs. having no daylight.

- 0111 vs. 1111: to measure the influence of minimum electric lighting when there is maximum simulated daylight available.

- 0111 vs. 3000: to measure the influence of having maximum simulated daylight vs. maximum electric lighting.

- 0111 vs. 3111: to measure the influence of having maximum electric lighting when there is maximum simulated daylight available.

- 1111 vs. 3111: to measure the influence of having minimum electric lighting vs. maximum electric lighting when there is maximum simulated daylight.

- 3000 vs. 3111: to measure the influence of having maximum simulated daylight when there is maximum electric lighting available.

In addition to the mentioned comparisons, we assessed if participants final lighting settings differed based on the default condition they were in. We also analysed if participants' personality (openness, conscientiousness, extraversion, agreeableness, and neuroticism) had any influence on participant's final lighting setting depending on the default setting they initially started with. In the last set of analyses, we examined whether participants' environmental views or values had an influence on their decisions to keep or adjust the default lighting settings. 


\subsection{IVE setup and lighting simulations}

Prior to conducting this experiment, a pilot study was completed in order to evaluate the virtual office space as well as the experimental procedures (Heydarian, Pantazis, Carneiro, Gerber, \& Becerik-Gerber, 2015). Based on the pilot study, a number of adjustments to the models were made to improve participant's interactions with the virtual space and their sense of presence with the IVE. The basic geometry and structure (e.g., walls, floor and ceiling, windows and etc.) of the office space was designed in Revit 2015 (Figure 3 - box 1a). The Revit model was imported to 3ds Max to optimize the space by adding furniture, materials, and textures to the different objects in the room (Figure 3 - box 1b). The lighting, reflection, and shadows were also set in 3ds Max for every different combination of daylighting and electric lighting that the participants could possibly choose. To make the models look photo-realistic in the IVE, they were rendered to texture in 3ds Max. To achieve this, at first we created the UV maps for every object in the office space in 3ds Max. We then included materials and textures for every object (e.g., furniture, walls, ceiling, and etc.) in the office by setting up and adding texture/diffuse colour channels, normal channels, specular channels, and occlusion channels through 3ds Max and V-Ray rendering engines. Lastly, we rendered to texture all 32 scenes based on their specific lighting settings to ensure the objects look realistic. Figure 4 shows our workflow for adding the materials, textures, and different maps to ensure the 3D model looks realistic. Each rendered 3D model carried a set of light maps that were imported to Unity 3D and were manually assigned to each corresponding scene (Figure 3 - box 4). Prior to transferring the $3 \mathrm{D}$ models to Unity $3 \mathrm{D}$, the same $3 \mathrm{D}$ models and the settings defined in $3 \mathrm{ds}$ Max (including all the lighting settings, location, orientation, weather condition, and etc.) were passed along to Rhinoceros 3D and Grasshopper for environmental analysis (Figure 3 - box 3.1).

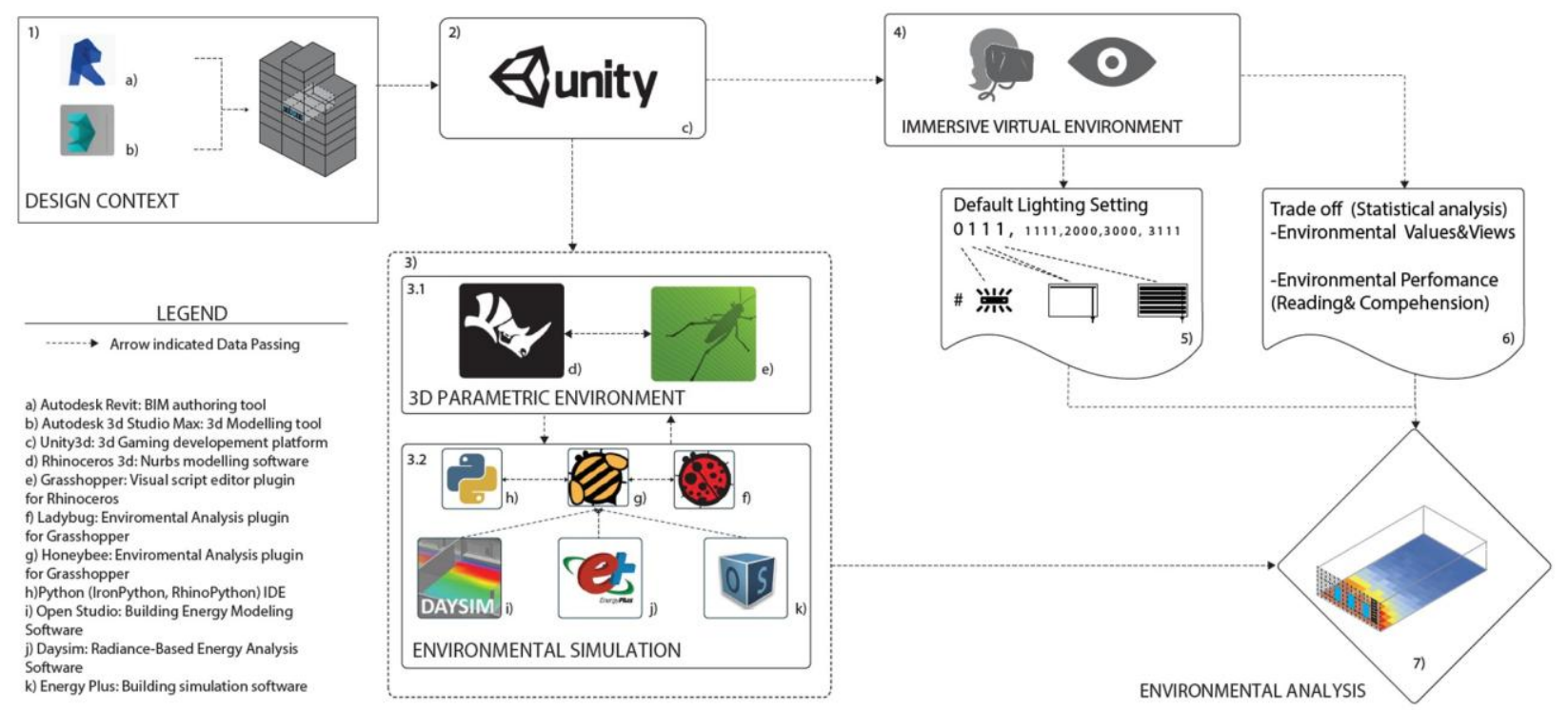

Figure 3 - Apparatus setup and the modeling and simulation process used in this experiment 


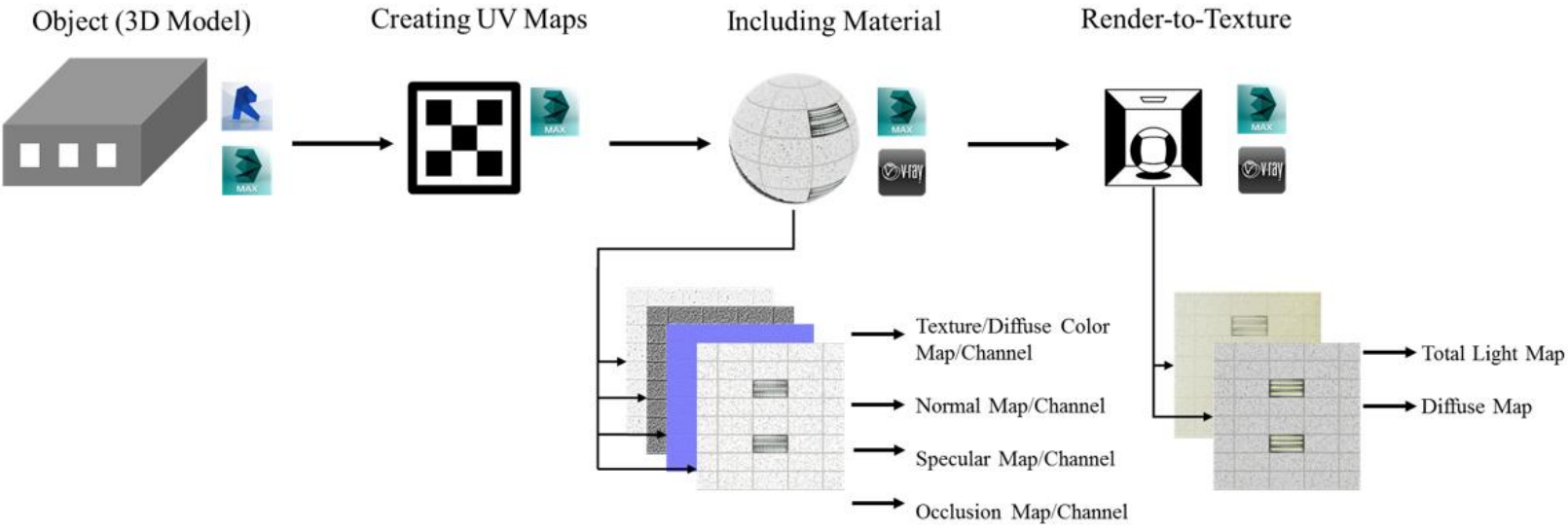

Figure 4 - Render-to-texture workflow for every object in each of the 32 scenes

In order to ensure the lighting settings in 3ds Max were realistic and representative of real-life values, we evaluated all 32 scenes by simulating the lighting settings using Ladybug and Honeybee plugins (open source plugins for Grasshopper 3D - Rhino plugin (Roudsari, Pak, \& Smith, 2014). As a result of this simulation, we were able to calculate the approximate illuminance distribution in the designed office space based on the settings we defined in 3ds Max@ (Figure 3 - box 3.2). Ladybug allows for a full range of environmental analyses in a single parametric platform and Honeybee connects Grasshopper3D to EnergyPlus, Radiance, Daysim, and OpenStudio software for building energy and day lighting simulation with an intend to provide parametric platform based on many features of these simulation tools (Figure 3 - box 3.2). Similar to 3ds Max, we used the V-Ray plugin in Rhino to assign specific materials and settings in our models to ensure the same materials and settings as the 3ds Max's rendered models are used. Additionally, by setting up the scenes adequately both in 3ds Max and Rhino (e.g., use correct scene scale, photometric lights, plausible materials etc.), we were able to produce renderings as close to the environmental analysis engines (in this case Radiance and Daysim) as possible.

In order to keep all the variables constant that could potentially influence the outcome of the study, the modelled office was set to be located at Los Angeles and the simulations were performed at 2:00 PM, May $22^{\text {nd }}$. Figure 5 provides the lighting simulation for the five default lighting settings. It is important to note that the lighting and environmental analyses performed in Ladybug and Honeybee were to ensure the lighting settings and distributions that were defined in 3ds Max were realistic and they were proper representation of a physical office space. Additionally, through these analyses, we ensured that the lighting levels were within the IESNA (Illumination Engineering Society of North America) requirements, which recommends for office-related activities, the minimum available lighting needs to be approximately 300-500 lux. 
Figure 5 - Illuminance distribution throughout the room and on the surface of the table where the passages were located for participants to read

The designed space had no surrounding buildings and the office space was isolated from the rest of building elements and components (i.e., the office space was placed by itself in the 3D space). The lighting settings in 3ds Max were set to represent realistic settings. For example, the electric lighting in the room was set up to represent cool white fluorescent lighting, which is commonly used in office buildings (colour temperature of approximately 5500K). Since the sky in the virtual environment was set to represent a blue sky, in our Ladybug and Honeybee simulations, the sky and sun conditions were set be cumulative sky and the IES file "Z_1_54T5HO_SMRA10.ies" was used for the specifications of the electric lighting (RAD materials for floor: default 'interior floor' from honeybee library; for roof and walls: RGB reflectance $=0.8$, roughness $=0.05$, spectacularity $=0$, and for windows: RGB transmittance $=0.3$, refractive index $=1.52$ ).

The 32 models were then exported as FBX files from 3ds Max and were imported into Unity 3D game engine (Figure 3 - box 4). Within Unity, interactive options were then programmed. These interactive options were designed to allow participants to use the light switches to turn the lamps on and off or to open or close the shades. Other interactive options were also added to allow participants to read over the passage and navigate in the room. Apart from programming these interactive options, Unity was also used to connect the IVE equipment to the designed virtual office space. The equipment included an Oculus DK2 Head-Mounted Display (HMD), an Xbox-360 controller, and a positional tracker that would track the participant's head and neck movements.

\subsection{Experiment procedure}

Prior to the experiment, participants were provided with a consent form, where a brief description about the experiment was included. This description provided information about the IVE environment without disclosing any information that could potentially influence participants' decisions during the experiment. Once participants reviewed and agreed to the consent form, they were asked to fill out The Big Five personality test. Following that, they were provided with a brief training in order to get a better understanding of the virtual environment, learn how to navigate within the space using the Xbox controller, and how to interact with different objects in the virtual room. For training purposes, a 
previously designed virtual space (different than the experimental space) was used to avoid any possible learning effects and biases that could possibly influence participant's decision making during the experiment. Once participants were satisfied and comfortable with navigating within the virtual space, they were asked to remove the HMD and report if they felt any motion sickness or had any concerns or issues about the IVE. It is important to note that no motion sickness or any other health issue was reported during the experiments.

Participants were randomly assigned to one of the five default setting groups (32 participants per each group). They were told that their task in the room was to read over a passage and answer a set of questions based on the passage. Once they entered the virtual office space, they were instructed to get a feeling of the available lighting in the room and decide whether they would like to keep the default lighting setting or adjust it to another setting. If the participants decided to adjust the default lighting setting, they were told they can open/close each shade to increase/decrease the available simulated daylighting as well as turn on/off the fluorescent lamps by manually interacting with the light switch next to the entrance. If they were interested in adjusting the lighting setting, they were instructed to adjust it to their most preferred lighting levels. Figure 6 shows a participant adjusting the lighting setting to his preferred lighting level.

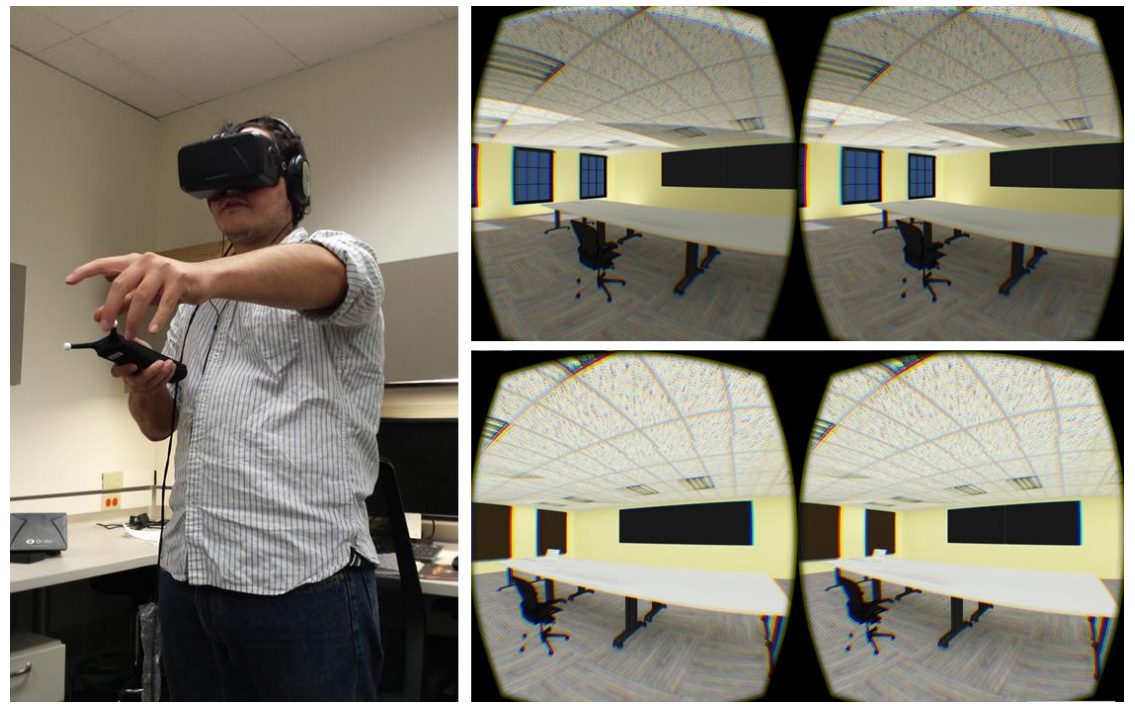

Figure 6 - Participant adjusting the default lighting setting to his preferred lighting setting

Once the participants were comfortable with the lighting setting (either by keeping the default setting or adjusting the setting), their final lighting choice was recorded and they were instructed to read over the passage located on the table in the middle of the room. The passage was directly placed in front of a chair located in the middle of the room at a constant viewing distance and angle for all participants. The amount of time (in seconds) that the participants took to read over the passage was recorded. They were then asked to remove the HMD and answer a number of questions about the passage. Lastly, they were asked to answer a number of questions related to their environmental views and values. They were then thanked for participating and dismissed from the experiment. On average the length of each experiment was in the range of 30 minutes to 45 minutes.

\section{Results and analyses}

Table 1 summarizes the experiment results with the numbers and percentages of participants keeping or adjusting the default lighting settings. Group 1 (0111) data show that $69 \%$ of the participants kept the default setting. Similar effects are also seen in group 2 (1111) and group 5 (3111), where $75 \%$ and $56 \%$ of 
the participants kept the default settings, respectively. This effect was not seen in groups 3 (2000) and 4 (3000), where there was no simulated daylight available (41\% of the participants kept the default setting in 2000 and $31 \%$ in 3000 ).

Table 1 - Participants who kept vs. adjusted the default settings

\begin{tabular}{|c|c|c|c|c|}
\hline Condition & \# kept & \# adjusted & \% kept & \% adjusted \\
\hline Group 1 (0111) & 22 & 10 & 69 & 31 \\
\hline Group 2 (1111) & 24 & 8 & 75 & 25 \\
\hline Group 3 (2000) & 13 & 19 & 41 & 59 \\
\hline Group 4 (3000) & 10 & 22 & 31 & 69 \\
\hline Group 5 (3111) & 18 & 14 & 56 & 44 \\
\hline
\end{tabular}

\subsection{Influence of simulated daylighting in default settings}

We performed "between groups" comparisons, where we analysed if participants' propensity to keep or adjust the lighting settings differed between the default conditions. At first, a comparison was performed between the groups that had all three shades open as their default lighting settings $(0111,1111$, and 3111) and the groups that only had electric lighting in the room (2000 and 3000). This analysis allowed us to better understand whether having simulated daylight available overall compared to having no daylight as a default setting would influence participants' propensity to keep the default setting. A chi-square $\left(\chi^{2}\right)$ analysis revealed that a significantly greater percentage of participants found the lighting conditions acceptable and kept the default if they were in a condition with all of the shades open initially than if they were in a condition with no shades open initially, $\chi^{2}(1, \mathrm{~N}=160)=14.61, p=0.00013$. This analysis reveals that participants are more likely to keep the default lighting, overall, when all of the shades are open than when there are no shades open. In the following analyses, we compare each of the relevant conditions individually to each other.

Next, we compared participants' propensity to keep the default in 0111 and 3000 . With this comparison, we assessed the influence of having maximum simulated daylight available without any electric light versus having maximum electric light available without any simulated daylight. A chi-square $\left(\chi^{2}\right)$ analysis revealed that a significantly greater percentage of the participants kept the lighting setting if they were in a condition with only maximum daylight as default than if they were in a condition with only maximum electric light as default, $\chi^{2}(1, \mathrm{~N}=64)=9, p=0.0027$.

Lastly, we examined the influence of having simulated daylight available between a group that had maximum electric light and maximum daylight available (3111) as default and a group with only maximum electric light available as default (3000). A chi-square $\left(\chi^{2}\right)$ analysis revealed that a significantly greater percentage of the participants kept the lighting setting if they were in a condition with maximum daylight and electric light (3111) available as default than if they were in a condition with only maximum electric light $(3000)$ as default, $\chi^{2}(1, \mathrm{~N}=64)=4.06, p=0.044$. Similar to the previous findings, this analysis reveals that participants are more likely to keep the default lighting when there is maximum simulated daylighting available.

We conducted an additional analysis in order to ensure that our effects are due to the availability of the simulated daylighting vs. electric lighting in the initial lighting setting rather than due to the differences in the illuminance levels. To measure whether the higher or lower illuminance levels of the default conditions had any influence on participants' propensity to keep or change the default settings, we ran a logistic regression where we analysed whether the "illuminance levels" of the initial setting (i.e., the 
average room's lux value for each condition was used as a predictor) had an effect on the participants' choices to keep or change the initial setting. We did not find that illuminance of the initial setting (higher or lower illuminance levels) had a significant effect on participants' choice $(\beta=-0.001, p=0.43)$.

\subsection{Participant's lighting adjustments and final lighting settings}

We also assessed the lighting setting participants chose if they adjusted the default setting. Figure 7 shows how many participants kept the default setting, increased/decreased the daylight/electric lighting settings. As we can see, the participants in the default setting with only electric lights and no simulated daylight (2000 and 3000) were very likely to open the shades if they changed the default setting (59\% in 2000 and $68 \%$ in 3000). Of the small percentage of participants, who changed the default setting when maximum daylight was available in the room, many of them increased the electric lights only (25\% in 0111 and $16 \%$ in 1111) without decreasing the amount of simulated daylighting (only 6\% in both 0111 and 1111 settings decreased daylighting).

When there was maximum electric lighting available, 22\% in default setting 3000 and $35 \%$ in default setting 3111 decreased the amount of electric lights in the room. However, no participant in default setting 1111 solely decreased the amount of electric light. In default 2000, where all of the participants preferred to increase the default lighting setting, $37 \%$ of the participants only increased the amount of simulated daylighting in the room, while only $6 \%$ of the participants increased both, daylighting and electric lights. These results show that default lighting setting has an effect on the participant's behaviour and decision in keeping or adjusting the available lighting. We also examined how the default lighting settings affected participants' overall final lighting choice. We combined participants who were in default conditions with only electric light and no simulated daylight (2000 and 3000) into the "No Shades Open" group and those who were in default settings with all of the shades open and some or no electric light into the "All Shades Open" group $(0111,1111$, and 3111). In their final lighting choices, the participants were significantly more likely to have all of the shades open if they were in the "All Shades Open" group than if they were in the "No Shades Open" group, $\chi 2(1, \mathrm{~N}=160)=69.82, \mathrm{p}<0.0001$. Participants were also significantly more likely to have some of the shades open if they were in the "All Shades Open" group than if they were in the "No Shades Open" group, $\chi 2(1, N=160)=50.40, p<0.0001$.

Next, we combined participants in the default conditions with all of the electrics lights on (3000 and 3111 ) into the "All Electric Lights" group. We compared the percentage of participants, who had all of the electric lights on in the final choice in the "All Electric Lights" group to the 0111 default setting (where there are no electric lights on). Participants were significantly more likely to have all of the electric lights on if they were in the "All Electric Lights" default setting than if they were in the default setting with no electric lights on (0111), $\chi 2(1, \mathrm{~N}=96)=23.02, p<0.0001$. 
Figure 7 - Participant's final lighting setting in each group

\subsection{Participant's performance within and between group comparisons}

In order to evaluate whether final lighting settings had an influence on participants' performance, their reading speed and comprehension were measured in their final lighting setting. If the participants kept the default, then the default lighting setting was considered as their final choice; if they decided to change the default, then the changed condition was considered their final choice. Through this process, first we assessed if participants perform better in some lighting settings than other lighting settings (e.g., no electric light vs. some electric lights). Second, we assessed if participants' performance was affected by whether they kept the default setting or changed the default setting.

Using ordinary least square regression (OLS), we assessed if participant's final lighting choice affected their performance in that setting (e.g., do people perform better if they choose to have all of the shades open or not?) Participants were marginally significantly more likely to read faster if they chose to have all of the shades open than those who chose to not have all of the shades open $(\beta=.38, p=.068)$. Specifically, participants who had all of the shades open read 0.38 more words per second than those who did not have all the shades open. Additionally, participants who chose only all electric lights performed marginally significantly worse on the comprehension questions than those who chose to not have all of the electric lights on $(\beta=-8.87, p=.066)$. Specifically, participants who had all of the electric lights on scored $8.87 \%$ lower on their comprehension than those who did not have all of the electric lights on. Lastly, participants who chose to have no electric lights on performed significantly better on the comprehension questions than those who chose to not have some or all of the electric lights on $(\beta=10.89, p=.050)$. Specifically, participants who chose to have no electric lights on scored $10.89 \%$ better on their comprehension than 
those who had electric lights on. This finding suggests that participants perform better in simulated daylighting settings compared to environments lit with only electric lighting.

In terms of the evaluation regarding if the participants' performance was affected by keeping or changing the default settings, the participants who changed the default settings did not perform significantly better for the comprehension and reading speed measure in their final lighting setting than those who kept the default.

\subsection{Questionnaire analysis}

In the last set of analyses, we analysed participants' personality traits, responses regarding the decisions behind their final choices, as well as whether their environmental views and values had an influence on their propensity to keep or adjust the default settings. A set of questions asked participants about their motivations to keep the default settings or in cases that they adjusted the lighting setting, they were asked to identify the reason behind the adjustments they made.

The only motivating factor that all participants who kept the default lighting setting identified was that the default lighting was sufficient for them to perform the reading task. Among the participants who "only opened the shades," 95\% mentioned they prefer natural light more, while 5\% mentioned it was easier for them to open the shades instead of increasing the number of electric lights. In the conditions, where the participants kept the default electric lights and decreased the amount of simulated daylight, 20\% mentioned that they prefer to have electric light over simulated daylight, $40 \%$ identified that it was easier to adjust the shading systems, and $40 \%$ mentioned they just preferred to have less lighting available regardless of the source of lighting. Among the participants who only increased the electric lighting, only $25 \%$ mentioned that they preferred to have electric lights over natural light while $33 \%$ mentioned it was easier to turn the electric lights on over adjusting the shades. The remaining of the participants who chose this option were in default conditions 0111 and 1111, where all the shades were open and in order to increase the available lighting, participants could only increase the electric lighting levels. Eighty-eight percent $(88 \%)$ of participants who were in default setting 2000 and increased both electric lighting and simulated daylighting indicated that they preferred to have both sources of lighting when performing office related activities; $22 \%$ mentioned that although they preferred to increase the lighting levels, they also were interested in interacting with the IVE space. Lastly, $75 \%$ of the participants who decreased both electric lighting as well as the simulated daylighting levels (default settings 1111 and 3111) stated that they thought the room was too bright (all of these participants were in 3111 default setting), and 25\% mentioned that they preferred to have less lighting when doing tasks similar to the assigned task during the experiment.

The results of occupants' personalities on the choice of lighting setting show that in the "default settings group", high neurotic people's tendency to keep the initial lighting condition depended on if the initial lighting setting was 3111 or $3000, \beta=1.72, \chi 2(1)=3.86, p=.050$. Floodlight analysis revealed that individuals with a score above 3.09 (out of 5) on the neurotic scale were significantly more likely to keep the initial lighting conditions in the 3111 condition than the 3000 condition (Johnson Neyman Point $=$ $3.09, \mathrm{p}<.05$ ). We also found that if neurotic people change the default condition, they are more likely to decrease the amount of electric lights, $\beta=.92, \chi^{2}(1)=3.98, p=.046$, and less likely to close the blinds, $\beta$ $=-.22, \chi 2(1)=7.30, \mathrm{p}=.007$.

Statistical analysis revealed that environmental views and values have no significant effects on individual's propensity to keep or change the default settings. This may be due to the fact that the sample of participants used in this experiment were higher than average on environmental values and views measures, leaving little variance in the data to detect any significant effect. Statistical analysis also 
revealed that no significant difference exists between individual's gender, and age and their propensity to keep or adjust the default lighting setting.

\section{Discussion}

The study presented in this paper assessed how different default settings affect participant's propensity to keep or change the lighting settings. The results revealed that participants were significantly less likely to change the default lighting setting if the such settings had maximum simulated daylight available (0111, 1111, or 3111) than no daylight available at all (2000 and 3000). Additionally, of those participants, who changed the default lighting setting within the "Only Electric Lighting Group" (2000 and 3000), they were very likely to change the default lighting setting to have some or all of the shades open. These combined analyses suggest that participants had a strong preference for simulated daylight rather than electric light.

The default lighting settings had a significant impact on people's overall lighting choices. Participants were more likely to choose to have the shades open in their final choice if the default setting had maximum simulated daylight available than if there were no daylight in the default setting. They were significantly more likely to have all of the electric lights on in their final choice if the default setting had all of the electric lights on. This suggests a "stickiness" of the default conditions; people are more likely to have a final choice with some resemblance to the default choice. Prior research has shown how defaults can affect a variety of other choices. However, to the best of our knowledge, this is the first research attempt that studied how defaults can largely influence people's lighting choices, especially lighting choice of daylighting vs. electric lighting, in order to be more motivated to choose a more energy efficient option. As lighting systems are responsible for significant amount of electricity usage in buildings and changing occupant behaviour has been proven to be an effective way to reduce energy, the findings presented in this paper have considerable implications to "unconsciously" influencing the occupant's energy-consumption behaviour. This default manipulation is free of cost and very easy to implement, revealing the practicality of the findings of this study.

Participants performed better in conditions where all shades were open and maximum simulated daylight was available in the room. This finding also suggests that these defaults could work positively to benefit not only the facility manager in charge of building performance but also the end-users of office buildings, namely the building occupants, by potentially increasing their productivity. Although other factors (e.g., psychological factors, etc.) can influence performance, there should be an equal distribution of participants with various psychological or physical differences across conditions due to the random assignment of participants to each condition.

The study also may have large implications for architects, engineers, facility managers, and building stakeholders. If building offices are designed in a way to increase the availability of daylighting, occupants may be less likely to use electric light if the default lighting is set in a way to provide lighting within their preferred levels while using mostly daylighting. Although such designs must account for other factors that could influence building energy consumption (e.g., heating and cooling systems), we can improve the lighting electricity consumption through improved design methods and axioms by incorporating human behaviour data. Participants' personality traits also showed that they could have an influence on their tendency to keep or adjust the default settings. Although we recommend further research needs to be done in this area, by knowing participants' personality traits, facility managers can improve the lighting energy consumption based on the occupant's preferences. For instance, if we know an occupant is a person ranks higher on neuroticism, prior to his/her entrance to his/her office we can ensure the shading systems are fully open in order to have him/her use less electric lights in the room.

\section{Limitations and future work}


Although the results are promising in terms of encouraging pro-environmental behaviour in buildings, there still exists a number of limitations that we plan to address in the near future. For instance, in the presented study, the virtual model was set to show the illuminance distribution of Los Angeles clear skies on a summer day at 2:00 PM. We plan to collect more data from the participants at different hours throughout a work day as well as under different environmental conditions (e.g., cloudy weather, variation of available daylighting, different seasons, etc.) in order to better understand the influence of default settings, as well as occupant's lighting preferences. The presented experiment was focused on a single occupancy office space where the participants had the freedom of interacting and adjusting the lighting settings based on their preferences. In multi-occupancy office spaces, occupants might not behave similarly due to social factors (e.g., conflicts or disturbance of other co-workers) and therefore, their behaviour and interactions with shading and lighting systems could be different. Future research should study the influence of such factors to better understand occupant behaviour in multi-occupancy office environments.

A limitation associated with IVEs is the exact representation of lighting in virtual environments. For instance, in order to create a more realistic virtual environment, we rendered our scene to texture and imported the proper light maps and diffuse color maps (according to each specific lighting configuration in each scene) to our model. In order to increase the realism of the space, tone-mapping techniques, such as Adaptive Reinhard, could be used in future studies to further increase the realism of the lighting in a virtual space (Larson, Rushmeier, \& Piatko, 1997; Murdoch, Stokkermans, \& Lambooij, 2015; Reinhard, Stark, Shirley, \& Ferwerda, 2002). To the best of our knowledge, no specific study has looked into assessment of tone-mapping or other configurations for HMDs. As a result of these limitation, although we expect our findings in this paper to be valid for physical environments, all the assessments performed by the participants are relative to the IVE setting and the equipment used in this study. Future studies must evaluate various tone-mapping techniques on Oculus Rift HMD as well as other HMDs to ensure more realistic environments can be visualized in IVE settings. Additionally, there is a need for future studies to benchmark participants' performance and how they perceive virtual environments to identical physical environments.

According to the data presented in Figure 7, the preferred illuminance level varies among participants. Although we did not find any significant effects between the illuminance levels and the participants' tendency to keep or adjust the default settings in this experiment, further evaluation should be made on different default settings with higher and lower illuminance levels to better understand occupant behaviour in office environments. Additionally, further evaluation should be made in physical environments to validate this conclusion, which we plan to study in our future work.

As part of our on-going work, we plan to further study occupant's lighting preferences and how different behavioural and environmental factors could influence occupant's building-interaction behaviours. With the goal to establish a bridge between occupant behaviour, architecture, building design features, and energy efficiency, as part of ongoing and future work, we also plan to explore how different architectural design options (e.g. spatial configurations, room geometries, type and size of windows, materials and etc.) could influence the occupant's behaviour to be more energy efficient. To achieve this, we are working on creating automated systems to generate new alternative designs through parametric and algorithmic design approaches, which lead to improved models that meet occupant's lighting preferences and consume less electricity. We are also interested in exploring the further use of IVEs to collect more accurate human behaviour data in relation to alternative designs and design features as well as incorporating such tools as design evaluation and feedback loops between the users of a building and designers. Establishing such feedback loop allows for a robust and effective communication among the users and designers, resulting in future buildings that increase the occupant comfort, performance, and well-being. 


\section{Conclusion}

In this study, we found that providing occupants with default lighting settings could significantly influence occupants' lighting choices depending on the initial setting. More specifically, we found that participants were significantly more likely to keep the default lighting setting if it had simulated daylighting than if it did not. If participants changed the lighting in the default conditions with no simulated daylighting, they were also more likely to increase the amount of daylighting. However, participants chose to have more daylighting available as their final lighting choice if they were initially assigned to a default setting with simulated daylighting rather than default lighting settings with no daylighting available. Lastly, we also found that participants perform better in conditions where daylight is available. These findings suggest that defaults might be an effective way to increase occupants' use of daylight in office spaces. For example, the results of this paper suggest that facility managers can largely affect occupant's lighting choices by initially setting up spaces to use a lower amount of energy.

Additionally, this paper reveals a novel method in which we can study how humans respond to various default conditions in a building setting. By using IVEs, we can control for various factors that are not possible in a physical environment, allowing us to be more confident that the effects we find are due to the manipulation rather than other unobserved confounds. Further, studying other preferences in IVE may be advantageous due to cost and time restraints, as structuring rooms with various design features to be studied in the physical world can be costly both in terms of money and time.

\section{References}

Adi, M. N., \& Roberts, D. J. (2014). Using Virtual Environments to Test the Effects of Lifelike Architecture on People. In Technologies of Inclusive Well-Being (pp. 261-285): Springer.

Aries, M. B. C., Veitch, J. A., \& Newsham, G. R. (2010). Windows, view, and office characteristics predict physical and psychological discomfort. Journal of Environmental Psychology, 30, 533541.

Begemann, S., Van den Beld, G., \& Tenner, A. (1997). Daylight, artificial light and people in an office environment, overview of visual and biological responses. International Journal of Industrial Ergonomics, 20, 231-239.

Bosch-Sijtsema, P. M., \& Haapamäki, J. (2014). Perceived enablers of 3D virtual environments for virtual team learning and innovation. Computers in Human Behavior, 37, 395-401.

Boyce, P. R., Veitch, J. A., Newsham, G. R., Jones, C. C., Heerwagen, J., Myer, M., \& Hunter, C. M. (2006). Occupant use of switching and dimming controls in offices. Lighting Research and Technology, 38, 358-376.

Brown, C. L., \& Krishna, A. (2004). The skeptical shopper: A metacognitive account for the effects of default options on choice. Journal of Consumer Research, 31, 529-539.

Brown, Z., Johnstone, N., Haščič, I., Vong, L., \& Barascud, F. (2013). Testing the effect of defaults on the thermostat settings of OECD employees. Energy Economics, 39, 128-134.

Carrico, A. R., \& Riemer, M. (2011). Motivating energy conservation in the workplace: An evaluation of the use of group-level feedback and peer education. Journal of Environmental Psychology, 31, 113. 
Choi, J. J., Laibson, D., Madrian, B. C., \& Metrick, A. (2002). Defined contribution pensions: Plan rules, participant choices, and the path of least resistance. In Tax Policy and the Economy, Volume 16 (pp. 67-114): MIT Press.

Choi, J. J., Laibson, D., Madrian, B. C., \& Metrick, A. (2004). For better or for worse: Default effects and 401 (k) savings behavior. In Perspectives on the Economics of Aging (pp. 81-126): University of Chicago Press.

Davidai, S., Gilovich, T., \& Ross, L. D. (2012). The meaning of default options for potential organ donors. Proceedings of the National Academy of Sciences, 109, 15201-15205.

de Korte, E. M., Spiekman, M., Hoes-van Oeffelen, L., van der Zande, B., Vissenberg, G., Huiskes, G., \& Kuijt-Evers, L. F. M. (2015). Personal environmental control: Effects of pre-set conditions for heating and lighting on personal settings, task performance and comfort experience. Building and Environment, 86, 166-176.

De Lillo, C., \& James, F. C. (2012). Spatial working memory for clustered and linear configurations of sites in a virtual reality foraging task. Cognitive processing, 13, 243-246.

Duarte, E., Rebelo, F., Teles, J., \& Wogalter, M. S. (2014). Behavioral compliance for dynamic versus static signs in an immersive virtual environment. Applied Ergonomics, 45, 1367-1375.

Dubois, M.-C., \& Blomsterberg, Å. (2011). Energy saving potential and strategies for electric lighting in future North European, low energy office buildings: A literature review. Energy and Buildings, $43,2572-2582$.

Dunston, P. S., Arns, L. L., Mcglothlin, J. D., Lasker, G. C., \& Kushner, A. G. (2011). An immersive virtual reality mock-up for design review of hospital patient rooms. In Collaborative design in virtual environments (pp. 167-176): Springer.

Edwards, L., \& Torcellini, P. A. (2002). A literature review of the effects of natural light on building occupants: National Renewable Energy Laboratory Golden, CO.

Fotios, S., \& Cheal, C. (2010). Stimulus range bias explains the outcome of preferred-illuminance adjustments. Lighting Research and Technology, 42, 433-447.

Galasiu, A. D., \& Veitch, J. A. (2006). Occupant preferences and satisfaction with the luminous environment and control systems in daylit offices: a literature review. Energy and Buildings, 38, 728-742.

Gilovich, T. D., \& Griffin, D. W. (2010). Judgment and decision making. Handbook of social psychology.

Heerwagen, J. (2000). Green buildings, organizational success and occupant productivity. Building Research \& Information, 28, 353-367.

Heydarian, A., Carneiro, J. P., Gerber, D., Becerik-Gerber, B., Hayes, T., \& Wood, W. (2015). Immersive virtual environments versus physical built environments: A benchmarking study for building design and user-built environment explorations. Automation in Construction, 54, 116-126.

Heydarian, A., Pantazis, E., Carneiro, J. P., Gerber, D., \& Becerik-Gerber, B. (2015). Towards Understanding End-User Lighting Preferences in Office Spaces by Using Immersive Virtual Environments. In Computing in Civil Engineering 2015 (pp. 475-482). 
Hong, T., D'Oca, S., Turner, W. J., \& Taylor-Lange, S. C. (2015). An ontology to represent energyrelated occupant behavior in buildings. Part I: Introduction to the DNAs framework. Building and Environment.

John, O. P., \& Srivastava, S. (1999). The Big Five trait taxonomy: History, measurement, and theoretical perspectives. Handbook of personality: Theory and research, 2, 102-138.

Johnson, E. J., Bellman, S., \& Lohse, G. L. (2002). Defaults, framing and privacy: Why opting in-opting out1. Marketing Letters, 13, 5-15.

Johnson, E. J., \& Goldstein, D. G. (2003). Do defaults save lives? Science, 302, 1338-1339.

Johnson, E. J., Hershey, J., Meszaros, J., \& Kunreuther, H. (1993). Framing, probability distortions, and insurance decisions: Springer.

Kuliga, S. F., Thrash, T., Dalton, R. C., \& Hölscher, C. (2015). Virtual reality as an empirical research tool - Exploring user experience in a real building and a corresponding virtual model. Computers, Environment and Urban Systems, 54, 363-375.

Larsen, C. R., Oestergaard, J., Ottesen, B. S., \& Soerensen, J. L. (2012). The efficacy of virtual reality simulation training in laparoscopy: a systematic review of randomized trials. Acta obstetricia et gynecologica Scandinavica, 91, 1015-1028.

Larson, G. W., Rushmeier, H., \& Piatko, C. (1997). A visibility matching tone reproduction operator for high dynamic range scenes. IEEE Transactions on Visualization and Computer Graphics, 3, 291306.

Li, C., Hong, T., \& Yan, D. (2014). An insight into actual energy use and its drivers in high-performance buildings. Applied Energy, 131, 394-410.

Logadóttir, Á., Christoffersen, J., \& Fotios, S. (2011). Investigating the use of an adjustment task to set the preferred illuminance in a workplace environment. Lighting Research and Technology, 43, 403-422.

Majumdar, T., Fischer, M. A., \& Schwegler, B. R. (2006). Conceptual design review with a virtual reality mock-up model. In Joint International Conference on Computing and Decision Making in Civil and Building Engineering.

Maldovan, K. D., Messner, J. I., \& Faddoul, M. (2006). Framework for reviewing mockups in an immersive environment. In CONVR 2006: 6th International Conference on Construction Applications of Virtual Reality (pp. 3-4): Orlando, Florida, August.

Maniccia, D., Rutledge, B., Rea, M. S., \& Morrow, W. (1999). Occupant use of manual lighting controls in private offices. Journal of the Illuminating Engineering Society, 28, 42-56.

Matusiak, B. S., \& Klöckner, C. A. (2016). How we evaluate the view out through the window. Architectural Science Review, 59, 203-211.

Moore, T., Carter, D., \& Slater, A. (2003). Long-term patterns of use of occupant controlled office lighting. Lighting Research and Technology, 35, 43-57. 
Murdoch, M. J., Stokkermans, M. G. M., \& Lambooij, M. (2015). Towards perceptual accuracy in 3D visualizations of illuminated indoor environments. Journal of Solid State Lighting, 2, 1-19.

Nilsson, A., Andersson, K., \& Bergstad, C. J. (2015). Energy behaviors at the office: An intervention study on the use of equipment. Applied Energy, 146, 434-441.

O'Brien, W., Kapsis, K., \& Athienitis, A. K. (2013). Manually-operated window shade patterns in office buildings: A critical review. Building and Environment, 60, 319-338.

Parsons, T. (2014). Virtual Teacher and Classroom for Assessment of Neurodevelopmental Disorders. In A. L. Brooks, S. Brahnam \& L. C. Jain (Eds.), Technologies of Inclusive Well-Being (Vol. 536, pp. 121-137): Springer Berlin Heidelberg.

Pertaub, D.-P., Slater, M., \& Barker, C. (2002). An experiment on public speaking anxiety in response to three different types of virtual audience. Presence: Teleoperators and virtual environments, 11, $68-78$.

Pichert, D., \& Katsikopoulos, K. V. (2008). Green defaults: Information presentation and proenvironmental behaviour. Journal of Environmental Psychology, 28, 63-73.

Reinhard, E., Stark, M., Shirley, P., \& Ferwerda, J. (2002). Photographic tone reproduction for digital images. ACM Trans. Graph., 21, 267-276.

Reinhart, C., \& Voss, K. (2003). Monitoring manual control of electric lighting and blinds. Lighting Research and Technology, 35, 243-258.

Roudsari, M., Pak, M., \& Smith, A. (2014). Ladybug: A Parametric Environmental Plugin for Grasshopper to Help Designers Create an Environmentally-Conscious Design.

Sanati, L., \& Utzinger, M. (2013). The effect of window shading design on occupant use of blinds and electric lighting. Building and Environment, 64, 67-76.

Sieminski, A. (2013). International energy outlook 2013. U.S. Energy Information Administration (EIA) Report Number: DOE/ELA-0484.

Tanja-Dijkstra, K., Pahl, S., P. White, M., Andrade, J., Qian, C., Bruce, M., May, J., \& Moles, D. R. (2014). Improving Dental Experiences by Using Virtual Reality Distraction: A Simulation Study. PLOS ONE, 9, e91276.

Thayer, B. (1995). Daylighting and productivity at Lockheed. Solar Today, 9, 26-29.

Tuaycharoen, N., \& Tregenza, P. R. (2007). View and discomfort glare from windows. Lighting Research and Technology, 39, 185-200.

Van Den Wymelenberg, K. (2012). Patterns of occupant interaction with window blinds: A literature review. Energy and Buildings, 51, 165-176.

Veitch, J. A., \& Newsham, G. R. (2000). Preferred luminous conditions in open-plan offices: research and practice recommendations. Lighting Research and Technology, 32, 199-212.

Waller, D., Beall, A. C., \& Loomis, J. M. (2004). Using virtual environments to assess directional knowledge. Journal of Environmental Psychology, 24, 105-116. 
Wei, M., Houser, K. W., Orland, B., Lang, D. H., Ram, N., Sliwinski, M. J., \& Bose, M. (2014). Field study of office worker responses to fluorescent lighting of different CCT and lumen output. Journal of Environmental Psychology, 39, 62-76.

Yu, Z., Fung, B. C., Haghighat, F., Yoshino, H., \& Morofsky, E. (2011). A systematic procedure to study the influence of occupant behavior on building energy consumption. Energy and Buildings, 43, $1409-1417$. 